\title{
Effects of Transcranial Direct-Current Stimulation Therapy on Primary Chronic Insomnia: A Proof-of Concept Clinical Trial
}

\author{
Jin-Sun Jun ${ }^{1}$, Tae-Joon Kim², Sun A Koo ${ }^{3}$, Ji-Sook Park ${ }^{3}$, Keun Tae Kim ${ }^{4}$, Tae-Won Yang ${ }^{5}$, \\ Jung-Ah Lim ${ }^{6}$, Jung-Ick Byun ${ }^{7}$, Jun-Sang Sunwoo ${ }^{8}$, Ki-Young Jung ${ }^{3}$ \\ ${ }^{1}$ Department of Neurology, School of Medicine, Kyungpook National University, Kyungpook National University Chilgok Hospital, Daegu, \\ ${ }^{2}$ Department of Neurology, National Center for Mental Health, Seoul, \\ ${ }^{3}$ Department of Neurology, Seoul National University Hosipital, Seoul, \\ ${ }^{4}$ Department of Neurology, Keimyung University Dongsan Medical Center, Daegu, \\ ${ }^{5}$ Department of Neurology, Gyeongsang National University College of Medicine, Gyeongsang National University Changwon Hospital, Jinju, \\ ${ }^{6}$ Department of Neurology, Hallym University College of Medicine, Gangnam Sacred Heart Hospital, Seoul, \\ ${ }^{7}$ Department of Neurology, Kyung Hee University Gangdong Hospital, Seoul, \\ ${ }^{8}$ Department of Neurology, Soonchunhyang University Seoul Hospital, Seoul, Korea
}

\author{
일차성 만성불면증 환자에서 경두개 직류전기자극법 치료 효과: 개념 증명 연구 \\ 전진선 ${ }^{1}$, 김태준 ${ }^{2}$, 구선아 $^{3}$, 박지숙 ${ }^{3}$, 김근태 ${ }^{4}$, 양태원 ${ }^{5}$, 임정아 ${ }^{6}$, 변정익 ${ }^{7}$, 선우준상 ${ }^{8}$, 정기영 ${ }^{3}$ \\ 경북대학교 의과대학 칠곡경북대학교병원 신경과, ${ }^{1}$ 국립정신건강센터 신경과, ${ }^{2}$ 서울대학교병원 신경과, ${ }^{3}$ \\ 계명대학교 동산의료원 신경과, ${ }^{4}$ 경상대학교 의과대학 창원경상대학교병원 신경과, ${ }^{5}$ \\ 한림대학교 의과대학 강남성심병원 신경과, ${ }^{6}$ 강동경희대학교병원 신경과, ${ }^{7}$ 순천향대학교서울병원 신경과 ${ }^{8}$
}

\author{
Received January 21, 2018 \\ Revised May 24, 2018 \\ Accepted July 9, 2018 \\ Address for correspondence \\ Ki-Young Jung, MD, PhD \\ Department of Neurology, \\ Seoul National University \\ Hospital, 101 Daehak-ro, \\ Jongno-gu, Seoul 03080, Korea \\ Tel: $+82-2-2072-4988$ \\ Fax: +82-2-2072-7424 \\ E-mail: jungky10@gmail.com
}

Objectives: To assess the effect and safety of transcranial direct-current stimulation (tDCS) in primary chronic insomnia. Methods: A one-month, double-blind, randomized, sham-controlled trial was performed. A total of 7 patients with primary chronic insomnia received tDCS using anodal $(n=3)$, cathodal $(n=2)$, or sham stimulation $(n=2)$. They were followed up at 1 week and 1 month after treatment. The primary outcome measures included improvement in total sleep time (TST), sleep latency (SL), and sleep efficiency (SE) at 1 month follow-up. Results: TST and SE were improved with tDCS at 1 month follow-up in all patients (100\%) of the anodal group, one (50\%) of the cathodal group, and one (50\%) of the sham group. tDCS improved SL at 1 month follow-up in two patients (67\%) of the anodal group, one (50\%) of the cathodal group, and none $(0 \%)$ of the sham group. With respect to adverse events, transient itching sensation occurred in one patient of the anodal group. None of the other groups reported adverse events. Conclusions: Our results suggest that tDCS may be effective and safe for treatment of primary chronic insomnia. A larger controlled study needs to be further investigated.

J Sleep Med 2018;15(2):37-42 Non-pharmacological treatment.

서 론

불면증은 수면 시작 장애, 수면 중 자주 깸과 다시 잠들기 어려움, 원하는 시간보다 지나치게 일찍 일어나는 것에 동반

This is an Open Access article distributed under the terms of the Creative Commons Attribution Non-Commercial License (https://creativecommons.org/licenses/by-nc/4.0) which permits unrestricted non-commercial use, distribution, and reproduction in any medium, provided the original work is properly cited.
되어 수면의 양과 질이 만족스럽지 않은 것을 특징으로 한 다. ${ }^{1}$ 이로 인해 낮 시간 동안의 기능과 삶의 질이 저하되고, 신체와 정신 질환 이환 위험성을 증가시켜 사회적, 직업적인 고통과 장해를 초래하게 된다. ${ }^{2,3}$

불면증에 대한 약물치료로는 벤조다이아제핀 수용체 효현 제, 항히스타민제, 삼환계항우울제, 멜라토닌 수용체 효현제 가 있으나 졸림, 정신운동 저하, 인지기능 저하 등의 부작용 
을 동반하며 특히 노인에서의 경우 그 부작용이 심각하게 나 타날 수 있어 주의를 요한다. ${ }^{4-8}$ 또한 비약물치료로 자극조절 요법, 이완훈련, 인지행동치료가 있으나 숙련된 수면 전문의 가 필요한 만큼 일상적인 의료환경에서 시행하기 어려운 경 우가 많다.,10 현재까지 알려진 약물치료와 비약물치료에도 불구하고 약 $30 \%$ 정도에서 질병관해가 이루어지지 않는다.

경두개 직류전기자극은 두피에 직류자극을 가하여 사람의 대뇌피질에 오래 지속되는 극성 특이적인 변화를 일으키는 비침습적인 뇌 활성 조절 방법으로 안전하고 부작용의 위험 이 적은 비약물치료법이다. 음성자극은 자극하는 동안과 자 극 이후에 피질 흥분성을 증가시키는 반면에 양성자극은 피 질 흥분성을 감소시킨다. ${ }^{11}$ 경두개 직류전기자극의 효과에 대해서는 여러 질환에서 연구가 시행되었고, 우울증, 만성통 증, 뇌졸중과 파킨슨병에서 대뇌피질의 흥분성을 조절하여 효과적인 치료로 사용될 수 있음을 보여주었다. ${ }^{12,13}$ 불면증에 대해서는 뇌성마비 후유증 환자와 양극성장애 환자에서 3 주 간 양성자극을 주었을 때 수면의 질이 향상되었다는 보고가 있으나 일차성 만성불면증 환자에서 경두개 직류전기자극의 효과에 대해서 평가된 바 없다..$^{44,15}$

본 연구는 일차성 만성불면증 환자를 대상으로 경두개 직 류전기자극 기기의 효과와 안정성을 평가하기 위한 개념 증 명 연구로서, 무작위 배정, 단일맹검, 모의대조군으로 설계한 임상시험이다. 연구의 목적은 1) 모의자극군에 비해 경두개 직류전기자극 사용군에서 객관적인 수면지표와 주관적인 수 면 개선을 확인하며 2) 경두개 직류전기자극의 안전성을 평 가하는 것이다.

\section{방 법}

\section{연구 대상}

2016년 3월부터 2017년 10월까지 서울대학교병원 수면클 리닉을 내원한 환자 중 불면증을 호소하는 자들을 대상자로 하였다. 모든 대상자는 STOP-BANG 설문지를 사전에 시행 하여 5점 이상인 경우 연구에서 제외하였고 수면전문가의 심 층 인터뷰를 통해 수면무호흡 또는 하지불안증후군 등의 다 른 수면장애 여부를 감별하였다. 일차성만성불면증의 진단은 국제수면질환분류 3판(International Classification of Sleep Disorders-3) 기준에 따라 만 19세 이상으로 3개월간 적어도 1 주일에 3회 이상 주관적인 수면 불편감(잠들기 어려움, 잠 유지하기 어려움, 일찍 깸)이 있으면서 일상생활 장애(피로, 집중력장애, 정동장애, 수행능력 저하 중 하나 이상)가 있는 경우 내려졌으며 불면증심각도지수(Insomnia Severity Index$\mathrm{K}, \mathrm{ISI}-\mathrm{K}$ )가 15 점 이상인 경우만 연구에 포함시켰다. 본 연
구의 제외 기준은 다음과 같다. 1) 뇌전증으로 진단을 받거나 경련의 병력이 있는 자, 2) 벤조다이아제핀 등의 항정신약물 변경이 1 개월 이내에 있는 자, 3) 문진 결과 수면무호흡증 또 는 주기성사지운동장애가 의심되는 자, 4) 정신지체를 동반한 자(IQ<70), 5) 임산부, 6) 왼손잡이 또는 양손잡이인 자.

본 연구는 서울대학교병원 임상시험심사위원회(IRB)의 승인을 받은 시험계획서(IRB 승인번호: 1509-061-703)에 따 라 진행되었고, 식품의약품안전처가 정한 임상시험관리기준 (Good Clinical Practice)에 준하여 실시되었다. 시험의 목적 및 시험기계의 특성은 임상시험 대상자에게 설명문을 통하여 설명하였고 동의를 한 대상자에게만 동의서 작성 후 시험에 참여하게 하였다.

\section{경두개 직류전기자극}

피험자 선정기준을 만족한 피험자를 무작위 배정 프로그 램에 의해 1:1:1의 비율로 양성자극군(anode group), 음성자 극군(cathode group), 모의자극군(sham group) 3 개의 군으로 무작위 배정하였다. 경두개 직류전기자극 기기는 Magstim (Eden Prairie, MN, USA)의 HDCkit를 사용하였으며 숙련 된 연구자가 수면센터에서 시행하였다. 자극은 기준전극을 좌측 어깨봉우리(acromion)에 위치시키고 활성전극을 우측 배측면 전두엽(뇌파 전극의 국제 10-20 체계의 F8 부위)에 위치시켰다. 자극은 환자군에 따라서 양성 또는 음성 자극을 $2 \mathrm{~mA}$ 의 크기로 월요일부터 금요일까지 5일간(D1 D5) 연속 적으로 매일 오후 5시에서 7시 사이에 20분간 주었다. 이전 연구에서와 같이 모의자극군의 경우 $2 \mathrm{~mA}$ 크기의 양성자극 을 15 초간 주었다. ${ }^{16}$

\section{수면일기}

환자들은 기초 방문 시부터 치료 완료 후 1 개월 기간 동안 매일 수면일기를 작성하여 수면 습관을 확인하였다. 수면일 기를 통해 수면잠복기, 총 수면시간[잠자리에 누워 있는 총 시간-(수면잠복기+수면 중 각성시간)], 수면효율[(총 수면시 간/잠자리에 누워 있는 총 시간 $\times 100]$ 을 계산하였다. 환자 들의 치료 전 상태를 평가하기 위해 경두개 직류전기자극 전 최소 7일 동안 수면일기를 작성하도록 하였다.

\section{치료 효과 판정}

일차 평가지표(primary outcome)로 치료 1개월 후(D35) 수면일기의 수면잠복기, 총 수면시간 그리고 수면효율의 변 화를 평가하고 각 수치들은 치료 완료 1주일 후(D12)부터 1 개월 후(D35)까지 기간 동안 평균값을 사용하였다. 이차 평 가지표(secondary outcome)로 치료 직후(D5)와 1주일 후 
(D12) 수면일기의 수면잠복기, 총 수면시간 그리고 수면효율 의 변화를 비교하였고 치료 직후 수치들은 치료 시작 다음 날(D1)부터 치료 완료 전일(D4)까지 기간 동안 평균값, 1 주일 후 수치들은 치료 완료일(D5)부터 1주일 후(D12)까지 기간 동 안 평균값을 사용하였다. 이 외에 치료 1 개월 후(D35) 피츠버 그수면질지수(Pittsburgh Sleep Quality Index Korean version) 와 불면증심각도지수(ISI-K), 치료 직후(D5), 치료 1주일 후 (D12), 그리고 치료 1개월 후(D35)의 리즈수면평가설문지 (Leeds Sleep Evaluation Questionnaire)와 전반적 임상 인상 척도(Clinical Global Impression)를 확인하였다.

\section{부작용 판정}

지금까지 보고된 경두개 직류전기자극에 의해 초래될 수 있는 부작용들인 피부 가려움, 피부자극 증상, 두통, 메스꺼 움, 피로감 등을 표를 만들어 모든 피험자에게 매 방문 시마 다 새로 발생한 부작용을 조사하여 기록하였다.

\section{결 과}

\section{연구 대상자의 특성}

연구 기간 동안 8 명이 본 연구에 등록되었으나, 이 중 1 명
은 무작위 배정 직후 동의를 철회하여 총 7명이 시험을 완료 하였다. 이들의 평균 나이는 57.4세(범위 41 69세)였고, 여성 이 5 명 $(71 \%)$ 으로 더 많았다. 각 환자의 인구학적 정보와 기 본 검사 결과는 Table 1에 제시하였다.

\section{경두개 직류전기자극 치료 전후 수면일기 결과 변화}

경두개 직류전기자극 치료 전과 치료 직후, 치료 1주 후, 치료 1 개월 후의 총 수면시간, 수면잠복기, 수면효율은 Fig. 1 과 Table 2에 나타내었다. 참여자의 수가 적어 계량적인 통 계 분석을 하기 어려워, 각 치료군별로 치료 전후의 변화를 기술하였다.

\section{양성자극군}

환자 1 은 치료 직후 총 수면시간의 증가, 수면잠복기의 감 소, 수면효율의 증가를 보이다가 치료 1 주 후 거의 치료 전 상 태로 악화되었다. 하지만 치료 1 개월 후에는 다시 세 지표에 서 뚜렷한 호전을 보였다. 환자 2는 치료 직후 총 수면시간과 수면효율에서 경미하게 감소하였으나 치료 1 주 후와 1 개월 후에는 치료 전 상태보다 증가하였다. 수면잠복기는 치료 이 후 오히려 증가하는 경향을 보였다. 환자 3은 치료 직후 세 지표에서 뚜렷한 호전을 보였고 치료 1 개월 후까지 지속되는

Table 1. Baseline characteristics of the patients

\begin{tabular}{|c|c|c|c|c|c|c|c|}
\hline Patient & 1 & 2 & 3 & 4 & 5 & 6 & 7 \\
\hline Group & Cathode & Cathode & Cathode & Anode & Anode & Sham & Sham \\
\hline Sex & $\mathrm{F}$ & M & $\mathrm{F}$ & $\mathrm{F}$ & $\mathrm{F}$ & $\mathrm{F}$ & M \\
\hline Age (years) & 69 & 53 & 61 & 57 & 63 & 41 & 58 \\
\hline Disease duration (years) & 7 & 2 & 30 & 15 & 0.5 & 6 & 1 \\
\hline Medications & None & $\begin{array}{l}\text { Amitrytiline } \\
\text { Etizolam } \\
\text { Fluoxetine }\end{array}$ & $\begin{array}{l}\text { Trazodone } \\
\text { Zolpidem }\end{array}$ & None & None & $\begin{array}{l}\text { Alprazolam } \\
\text { Lorazepam }\end{array}$ & $\begin{array}{l}\text { Melatonin } \\
\text { Pregabalin } \\
\text { Trazodone } \\
\text { Zolpidem }\end{array}$ \\
\hline Body mass index $\left(\mathrm{kg} / \mathrm{m}^{2}\right)$ & 24.0 & 19.0 & 19.9 & 22.1 & 26.4 & 32.0 & 23.0 \\
\hline
\end{tabular}

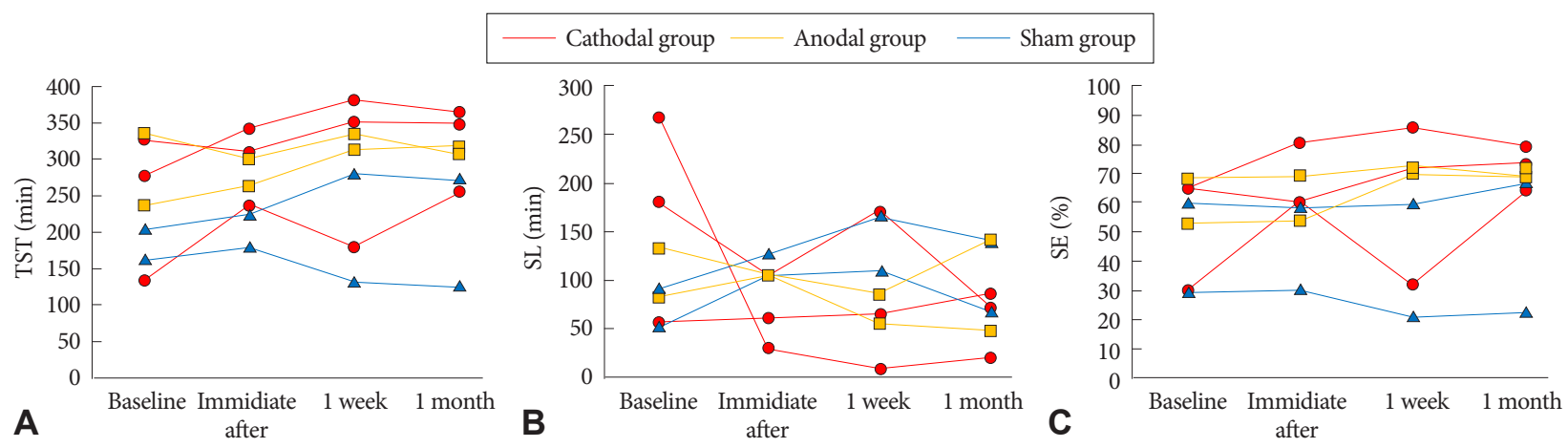

Figure 1. Sleep diary parameter changes in cathode group (red line), anode group (yellow line), and sham group (blue line). (A) TST, (B) SL, and (C) SE at baseline, immediate after treatment, 1 week and 1 month follow-up. TST: total sleep time, SL: sleep latency, SE: sleep efficiency. 
Table 2. Primary and secondary outcomes in cathode, anode and control groups

\begin{tabular}{|c|c|c|c|c|c|c|c|}
\hline Patient & 1 & 2 & 3 & 4 & 5 & 6 & 7 \\
\hline \multicolumn{8}{|l|}{ TST (min) } \\
\hline Baseline & $133 \pm 49$ & $327 \pm 36$ & $276 \pm 16$ & $335 \pm 13$ & $236 \pm 34$ & $204 \pm 24$ & $163 \pm 25$ \\
\hline Immediate after & $235 \pm 36$ & $307 \pm 42$ & $342 \pm 22$ & $300 \pm 22$ & $262 \pm 23$ & $225 \pm 32$ & $180 \pm 36$ \\
\hline 1 week & $178 \pm 26$ & $351 \pm 30$ & $380 \pm 45$ & $335 \pm 23$ & $312 \pm 36$ & $281 \pm 24$ & $132 \pm 42$ \\
\hline 1 month & $255 \pm 58$ & $347 \pm 52$ & $364 \pm 43$ & $308 \pm 34$ & $317 \pm 34$ & $274 \pm 22$ & $127 \pm 32$ \\
\hline \multicolumn{8}{|l|}{$\mathrm{SL}(\mathrm{min})$} \\
\hline Baseline & $180 \pm 72$ & $56 \pm 12$ & $267 \pm 8$ & $132 \pm 23$ & $82 \pm 21$ & $53 \pm 14$ & $92 \pm 12$ \\
\hline Immediate after & $104 \pm 24$ & $60 \pm 22$ & $29 \pm 5$ & $105 \pm 22$ & $105 \pm 32$ & $105 \pm 24$ & $127 \pm 32$ \\
\hline 1 week & $171 \pm 14$ & $64 \pm 12$ & $7 \pm 10$ & $85 \pm 32$ & $55 \pm 15$ & $110 \pm 24$ & $167 \pm 13$ \\
\hline 1 month & $72 \pm 14$ & $85 \pm 34$ & $19 \pm 6$ & $141 \pm 34$ & $47 \pm 14$ & $68 \pm 14$ & $142 \pm 24$ \\
\hline \multicolumn{8}{|l|}{ SE (\%) } \\
\hline Baseline & $29 \pm 11$ & $66 \pm 5$ & $64 \pm 4$ & $68 \pm 5$ & $53 \pm 4$ & $60 \pm 9$ & $30 \pm 9$ \\
\hline Immediate after & $60 \pm 4$ & $59 \pm 6$ & $81 \pm 6$ & $69 \pm 8$ & $53 \pm 12$ & $59 \pm 8$ & $30 \pm 6$ \\
\hline 1 week & $32 \pm 2$ & $71 \pm 4$ & $86 \pm 6$ & $72 \pm 9$ & $70 \pm 8$ & $60 \pm 6$ & $21 \pm 8$ \\
\hline 1 month & $64 \pm 4$ & $73 \pm 12$ & $79 \pm 8$ & $69 \pm 8$ & $72 \pm 4$ & $66 \pm 14$ & $23 \pm 4$ \\
\hline \multicolumn{8}{|l|}{ PSQI score } \\
\hline Baseline & 19 & 14 & 14 & 17 & 16 & 19 & 15 \\
\hline 1 month & 9 & 11 & 9 & 15 & 14 & 16 & 18 \\
\hline \multicolumn{8}{|l|}{ ISI score } \\
\hline Baseline & 25 & 20 & 21 & 21 & 21 & 23 & 16 \\
\hline 1 month & 5 & 11 & 14 & 17 & 6 & 21 & 20 \\
\hline \multicolumn{8}{|l|}{ LSEQ score } \\
\hline Baseline & 38 & 40 & 40 & 19 & 26 & 15 & 24 \\
\hline Immediate after & 78 & 78 & 59 & 52 & 52 & 16 & 37 \\
\hline 1 week & 79 & 75 & 69 & 39 & 56 & 34 & 36 \\
\hline 1 month & 70 & 97 & 63 & 52 & 60 & 15 & 8 \\
\hline \multicolumn{8}{|l|}{ CGI } \\
\hline Immediate after & 2 & 3 & 3 & 3 & 4 & 3 & 4 \\
\hline 1 week & 2 & 3 & 3 & 5 & 3 & 3 & 4 \\
\hline 1 month & 2 & 3 & 3 & 4 & 3 & 3 & 6 \\
\hline
\end{tabular}

Data regarding TST, SL, and SE are presented as mean \pm standard deviation. CGI: clinical global impression, ISI: Insomnia Severity Index, LSEQ: Leeds Sleep Evaluation Questionnaire, PSQI: Pittsburgh Sleep Quality Index, SE: sleep efficiency, SL: sleep latency, TST: total sleep time

양상을 보였다.

\section{음성자극군}

환자 4는 치료 직후부터 치료 1 개월 후까지 총 수면시간은 오히려 감소하였고 수면잠복기는 치료 직후부터 1 주일 후까 지 감소하였으나 치료 1 개월 후 다시 증가하였다. 수면효율 은 치료 전후로 변화가 미미하였다. 환자 5 의 경우는 치료 직 후부터 치료 1 개월 후까지 수면시간은 증가하였고 수면잠복 기는 치료 직후 증가하였다가 치료 1 주 후와 1 개월 후에는 치료 전보다 훨씬 감소하였다. 수면효율은 치료 직후 변화가
없었으나 치료 1 주일 후와 1 개월 후 증가하였다.

\section{모의자극군}

환자 6의 경우 치료 직후부터 치료 1 개월 후까지 총 수면 시간이 증가하였으나 수면잠복기도 함께 증가하는 양상을 보였다. 수면효율은 치료 1 주 후까지 큰 변화가 없다가 치료 1 개월 후에 다소 증가하였다. 환자 7은 치료 직후 총 수면시 간이 증가하였으나 이후 점차 감소하여 치료 1 개월 후에는 치료 전보다 감소하였다. 수면잠복기와 수면효율은 치료 이 후 오히려 악화되는 양상을 보였다. 


\section{경두개 직류전기자극 치료 전후 수면 설문지 점수 변화}

치료 전후 수면 설문지 점수 변화는 Table 2에 제시하였 다. 피츠버그수면설문지수, 불면증심각도지수, 리즈수면평 가설문지에서 양성자극군과 음성자극군 모두 치료 전과 비 교했을 때 치료 1 개월 후 점수가 호전되었으나 호전 정도는 양성자극군에서 더 컸다. 모의자극군 중 환자 6 은 치료 1 개 월 후 피츠버그수면설문지수와 불면증심각도지수에서 약간 의 호전을 보였으나 리즈수면평가설문지에서는 변화가 없었 고 환자 7은 세 설문지 점수에서 모두 호전을 보이지 않았다.

전반적 임상 인상 호전도의 경우 양성자극군은 3 명 모두 에서 호전이 있었으나 음성자극군의 경우 환자 4는 치료 직 후 약간의 호전이 있다가 이후 호전이 지속되지 않았으며 환 자 5는 치료 직후에는 호전이 없었으나 치료 1 개월 후 다소 호전이 있었다. 모의자극군의 경우 환자 6은 다소 호전이 있 었으나 환자 7은 치료 직후 호전 없이 유지되다가 치료 1개월 후 매우 악화되었다.

\section{치료 안전성}

본 연구에 참여한 7명의 임상시험 대상자 중에서, 일시적 인 피부 가려움을 양성자극군 한 명에서 보고하였다. 나머지 6명의 연구 대상자는 부작용이 없었다.

\section{고 찰}

본 연구는 일차성만성불면증 경두개 직류전기자극의 효과 및 안전성을 보기 위한 개념 증명 연구로서 총 8 명의 환자가 모집되었고 7명이 끝까지 연구를 수행하였다. 양성자극군 환자에서 총 수면시간 증가, 수면잠복기 감소, 그리고 수면 효율이 증가하는 경향성을 보였으며 음성자극군과 모의자극 군에서는 수면지표 호전의 경향을 보이지 않았다. 설문지를 통한 수면의 질 평가에 있어서는 각 그룹 간의 뚜렷한 경향 성의 차이는 없었다.

불면증의 병태생리에 대해서는 여러 가지 가설이 있으나 최근 과각성 모형(hyperarousal model)이 제시되면서 불면 증의 신경생리학적 기전이 주목받고 있다. 이는 불면증이 수 면촉진영역(ventrolateral preoptic nucleus)과 각성촉진영역 (hypothalamic orexin neuron)의 불안정에서 기인한다는 것 이다. 또한 여러 가지 뇌영상연구에서 불면증 환자는 대조군 에 비해 전전두엽의 활성도와 대사가 저하되어 있음을 보고 하였으며, 만성불면증에 대한 다양한 연구들에서 공통적으 로 각성 시에 전두엽-피질하 네트워크(fronto-subcortical network) 이상이 나타남을 보고하였다..$^{17-20}$ 이에 불면증 환 자에서 전두엽 활성을 조절하기 위한 방법으로 반복 경두개
자기자극 치료를 시행하였으며 약물치료와 인지행동치료와 비교했을 때 경두개 직류전기자극 치료가 수면구조 개선 효 과가 가장 좋고 치료 효과가 장기간 유지됨을 확인한 바 있 다. ${ }^{21}$ 본 연구에서 양성자극군은 음성자극군, 모의자극군과 비 교하였을 때 치료 직후와 1 달 후 수면지표들이 호전되는 경 향성이 있음을 확인하였다. 이는 자극으로 뇌기능조절(neuromodulation)을 하여 과각성을 개선, 전두엽 기능 개선을 하 여 불면증을 호전시켰다고 볼 수 있다. 특히 경두개 직류전기 자극 기기의 양성자극은 피질의 흥분성을 억제하므로 과각 성으로 발생하는 불면증이 개선될 수 있겠다.

본 연구는 세계 최초로 일차성 만성불면증에서의 경두개 직류전기자극 치료 효과를 평가한 연구로 그 의의가 있으나 몇 가지 한계점에 대한 고려가 필요하다. 우선 적은 수의 환 자로 인해 효과 평가에 제한점이 있다. 또한 경두개 직류전 기자극은 N-methyl-D-aspartate 수용체 의존 기전과 관련 하여 장기적인 효과를 일으킨다고 알려져 있으나,22 본 연구 는 평가 기간이 1 달로 짧아 장기간의 효과를 확인할 수 없었 다. 마지막으로 단일기관 연구로 선택편향의 위험성이 있을 수 있다. 그럼에도 불구하고 현재 연구는 일차성 만성 불면증 에서의 경두개 직류전기자극 치료 효과의 가능성을 보여주 며 추후 연구에서는 환자 수를 늘려서 단기간의 효과뿐만이 아니라 장기간 효과까지 확인해 보는 일이 필요할 것이다.

\section{Acknowledgments}

Ki-Young Jung was supported by Seoul National University Hospital (042015 0300).

\section{REFERENCES}

1. Schutte-Rodin S, Broch L, Buysse D, Dorsey C, Sateia M. Clinical guideline for the evaluation and management of chronic insomnia in adults. J Clin Sleep Med 2008;4:487-504.

2. Silber MH. Clinical practice. Chronic insomnia. N Engl J Med 2005; 353:803-810.

3. Kwon YN, Sung MJ, Cho HA, et al. Effects of an indigo blanket on insomnia symptoms: double blind, placebo-controlled, randomized pilot study. J Korean Sleep Res Soc 2014;11:33-37.

4. Wilt TJ, MacDonald R, Brasure M, et al. Pharmacologic treatment of insomnia disorder: an evidence report for a clinical practice guideline by the American College of Physicians. Ann Intern Med 2016;165:103112.

5. Sateia MJ, Buysse DJ, Krystal AD, Neubauer DN, Heald JL. Clinical practice guideline for the pharmacologic treatment of chronic insomnia in adults: an American Academy of Sleep Medicine clinical practice guideline. J Clin Sleep Med 2017;13:307-349.

6. Gray SL, LaCroix AZ, Hanlon JT, et al. Benzodiazepine use and physical disability in community-dwelling older adults. J Am Geriatr Soc 2006; 54:224-230.

7. Cumming RG, Le Couteur DG. Benzodiazepines and risk of hip fractures in older people: a review of the evidence. CNS Drugs 2003;17: 825-837.

8. Glass J, Lanctôt KL, Herrmann N, Sproule BA, Busto UE. Sedative hypnotics in older people with insomnia: meta-analysis of risks and 
benefits. BMJ 2005;331:1169.

9. Bootzin RR, Perlis ML. Nonpharmacologic treatments of insomnia. $J$ Clin Psychiatry 1992;53 Suppl:37-41.

10. Brasure M, Fuchs E, MacDonald R, et al. Psychological and behavioral interventions for managing insomnia disorder: an evidence report for a clinical practice guideline by the American College of Physicians. Ann Intern Med 2016;165:113-124.

11. Stagg CJ, Nitsche MA. Physiological basis of transcranial direct current stimulation. Neuroscientist 2011;17:37-53.

12. Boggio PS, Rigonatti SP, Ribeiro RB, et al. A randomized, double-blind clinical trial on the efficacy of cortical direct current stimulation for the treatment of major depression. Int J Neuropsychopharmacol 2008;11: 249-254.

13. Hansen N, Obermann M, Poitz F, et al. Modulation of human trigeminal and extracranial nociceptive processing by transcranial direct current stimulation of the motor cortex. Cephalalgia 2011;31:661-670.

14. Bola M, Prilloff S, Matzke S, Henrich-Noack P. Brain restoration as an emerging field in neurology and neuroscience. Restor Neurol Neurosci 2013;31:669-679.

15. Minichino A, Bersani FS, Spagnoli F, et al. Prefronto-cerebellar transcranial direct current stimulation improves sleep quality in euthymic bipolar patients: a brief report. Behav Neurol 2014;2014:876521.
16. Koo YS, Kim SM, Lee C, et al. Transcranial direct current stimulation on primary sensorimotor area has no effect in patients with drug-naïve restless legs syndrome: a proof-of-concept clinical trial. Sleep Med 2015; 16:280-287.

17. Altena E, Van Der Werf YD, Sanz-Arigita EJ, et al. Prefrontal hypoactivation and recovery in insomnia. Sleep 2008;31:1271-1276.

18. Nofzinger EA, Buysse DJ, Germain A, Price JC, Miewald JM, Kupfer DJ. Functional neuroimaging evidence for hyperarousal in insomnia. Am J Psychiatry 2004;161:2126-2128.

19. Spiegelhalder K, Regen W, Prem M, et al. Reduced anterior internal capsule white matter integrity in primary insomnia. Hum Brain Mapp 2014;35:3431-3438.

20. Riemann D, Nissen C, Palagini L, Otte A, Perlis ML, Spiegelhalder K. The neurobiology, investigation, and treatment of chronic insomnia. Lancet Neurol 2015;14:547-558.

21. Jiang CG, Zhang T, Yue FG, Yi ML, Gao D. Efficacy of repetitive transcranial magnetic stimulation in the treatment of patients with chronic primary insomnia. Cell Biochem Biophys 2013;67:169-173.

22. Reidler JS, Zaghi S, Fregni F. Chapter 12-neurophysiological effects of transcranial directcurrent stimulation. In: Coben R, Evans JR. Neurofeedback and neuromodulation techniques and applications. 1st ed. San Diego: Academic Press, 2011;319-349. 